\title{
Critical Review of Yasheng Huang's "Rethingking the Bejing
}

\section{Consensus"}

\author{
Long H. Vo *
}

\begin{abstract}
The unprecedented economic growth enjoyed by the People's Republic of China over the last few decades has attracted the attention of academics and policy-makers all over the world. The developing countries are not an exception and, in fact, many in Asia, Africa and Latin America may see the China model as an example of new development formula more effective than free markets. However, MIT professor Yasheng Huang pointed out that these countries, as well as China itself, should reconsider their future decision. His paper examining the nature of China model with regards to the principles of the Beijing Consensus, though could be improved upon, is a very intuitive work that provides valuable foundation to understand the truth from the facts. His ultimate message is that the China's growth path was actually remarkably conventional: one based on private ownership and ideas of free-market finance.
\end{abstract}

Keywords: Beijing consensus, economic models, growth strategy, growth measurements.

\section{Introduction}

Since the period known as the Reform era $^{1}$, a war-torn Chinese economy had experienced an unprecedented annual growth rate of $9.91 \%$ from 1979 to 2010 (International Monetary Fund, 2014), while largely avoiding periodic depressions in the world's economy. The amazing success of China's economic reforms, in contrast to the varying difficulties encountered by the former Soviet Union and Eastern European countries in their comparable transitions, has attracted worldwide attention. In 2004, an analyst from the United Kingdom, Joshua Cooper Ramo (Ramo, 2004), became the first to use the term "Beijing Consensus" to describe the general development principles that China adopted during this reform period. Over the past three decades, the wake of successive financial fiascos such as the energy crisis (1979), Mexican debt crisis (1982), Asian monetary crisis (1997) and the global financial crisis (2008) had provided ample inspiration for a large number of academics to promptly associated the China miracle with the end of free-market oriented principles and praised the new Chinese-style economic philosophy. In his 2008 paper, D. Rodrik rhetorically asked "The question now is not whether the Washington Consensus is dead or alive; it is what will replace it" (Rodrik, 2006) (p.974).

After 2008, though not explicitly, Chinese government officials had fully embraced the Beijing Consensus primary principle, the superiority of state control over private ownership. However, there had been continuous debates around the topic of whether or not the newly emerged China

\footnotetext{
*Faculty of Finance, Banking and Business Management, Quy Nhon University, Binh Dinh, Vietnam.

E-mail: vohailong@fbm.edu.vn

${ }^{1}$ Which was also famously associated with the dramatic, widespread economic and socio-politico change led by the visionary Deng Xiaoping, succeeding the devastating period of recession under Mao Zedong's Great Leap Forward era.
} 
model had ended the days of the once prevailed Western market-friendly framework know as "the Washington Consensus". Perhaps one of the more intuitive analyses to address this concern is a study by (Huang, 2011), titled "Rethinking of the Beijing Consensus".

In this paper, Huang adopted new approaches to examine the actual significance of many implications imposed by advocates of Beijing Consensus, and his main arguments basically countered these well-established principles. The most important point he made, in my view, is that Chinese economic performance was not as well and as consistent as was implied by previous analyses. The key factor led to his finding was the utilization of new measures of performance that track the living standard of Chinese, rather than the traditional China GDP data. This author then made a valuable observation, claiming that when using these measures, "China has performed the best when it pursued liberalizing, market-oriented economic reforms, as well as conducted modest political reform, and moved away from statist policies" (Huang, 2011) (p.2). In addition, he critically analysed and undermined one of the core "innovations" on which the Beijing Consensus was built: the role of the mixed ownership firms.

Based on these insights, Huang suggested a re-consideration of China current statist-oriented strategy, suggesting a revision of a more liberal policy framework that was, in his opinion, the root of Chinese improved performance during the 1980s. Interestingly, this revolutionary point of view was shared by (Jiang, 2011) in an article bearing the same name as Huang's.

This review intends to briefly summarize the major implications made in the paper, and provide some extensive criticism to the point that there should indeed be a reassessment of policy on China's behalf.

\section{First major argument: The inconsistent performance of China}

The first point Huang made is that China's impressive economic growth is not consistently robust overtime when he used the measurement of personal income. He then compared the growth of personal income with that of GDP during three "policy decades" (1978-1988, 1989-2002 and 20032008). In defence of using personal income measures, Huang illustrated that not only are these data more reliable than Chinese national GDP statistics (due to a number of technical and substantive reasons), but also are important in that they can be used to examine Chinese model from the welfare perspective. This justified his choice of including the average income and consumption of China rural area, as "GDP data does not break down economic performance among different groups of Chinese" (p.8). Also, addressing Chinese reform on social welfare grounds could help determine whether this model was a Pareto optimality, as was commonly believed in previous literature, as suggested by (Lau, Qian, \& Roland, 2000).

In order to emphasis the heterogeneity in Chinese performance, the author focused on contrasting the first two periods' data, which he stated to be directly correlated to the choice of entirely opposite policy directions. The most recent period under Hu Jintao and Wen Jiabao, however, experienced a number of both more and less liberal policies and it is very difficult to analyze their distinctive effects. Nevertheless, by presenting data on household income and GDP improvement across the three periods, Huang exposed a clear discrepancy between their growth patterns: while Chinese GDP average growth rates increased overtime with little difference, the personal income growth rate during the 1980s was greater than that of the 1990s, especially in the rural area:

The author used this observation to support the statement that there is no consistent Beijing model, and that "in fact China was more effective at enhancing welfare during the decade when it 
followed more liberal policies" (p.10). The divergence of GDP and personal income was extensively studied in his previous book (Huang, 2008), but was criticized by many as inaccurate, since the comparison failed to include the income of rural migrants, and thus underestimate Chinese overall income growth.

However, Huang proved that this omission of data, which was due to unavailability, actually did not affect the final implication, as demonstrated by the increasing gap between rural migrants' income and GDP per capital:

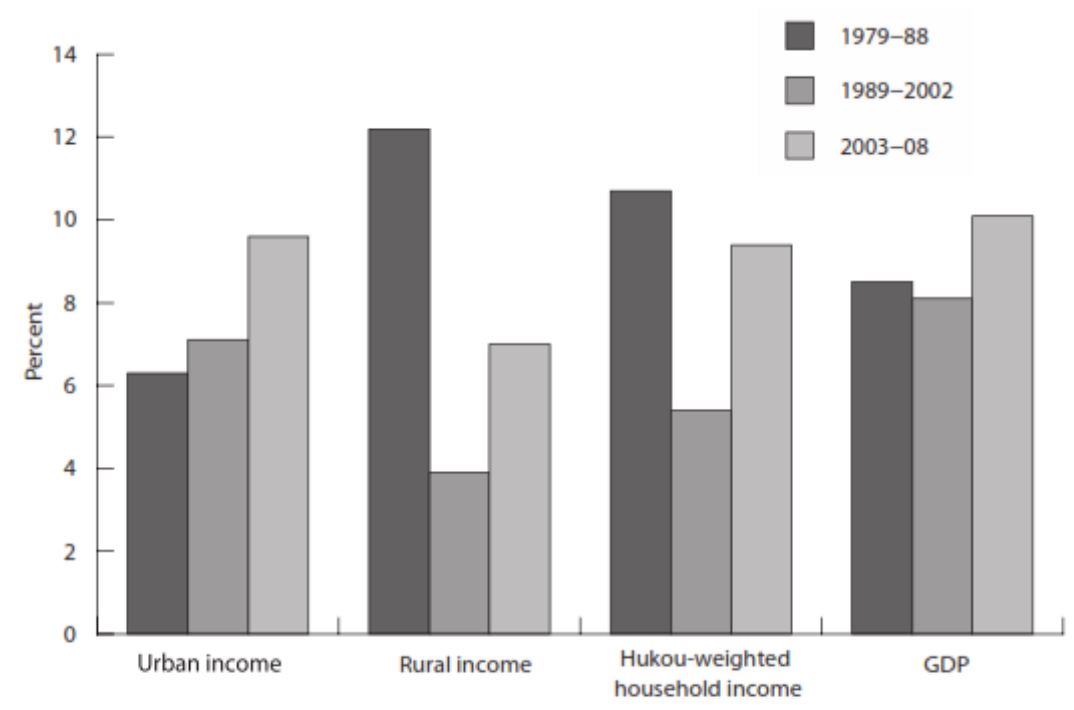

Source: Personal income data is based on annual National Bureau of Statistics (NBS) household surveys, and GDP data is from NBS, China Statistical Yearbook, multiple years.

Note: Both GDP and household income data are deflated to their 1978 values.

Figure 1: GDP and income growth from the three policy decades (values in 1978 prices and in per capita terms). Originally from (Huang, 2011), (p.9).

This phenomenon is also reflected in a recent report from (The Economist, 2012), which presented an interview with Li Wei, head of China Development Research Centre. Wei expressed his concern regarding China's prospect of becoming the world's largest economy, when the country's income per person still ranks around number 90: “(..) even if its GDP overtakes America's by the end of the decade, China will remain as poor as Brazil or Poland are today (...)".

\section{The Chinese 'models', not 'model'}

After addressing the diversity expressed in China's performance, Huang concluded that there was no single, static development model/theory that could explain this phenomenon. Therefore 
he regarded the debate on Beijing Consensus "is not about a steady state of where Chinese economic policies and institutions are but instead is about their movement overtime" (p.12). In particular, the author believed the data of Chinese income suggested the existence of at least two growth models, which either encouraged or discouraged overall welfare improvement. Based on this intuition, Huang developed analyses to examine the relevant question: which policy direction did China took leading to such diverse performance? The result suggests a positive correlation between the degree to which market-oriented reforms were adopted and the improvement in welfare.

As mentioned in the second section, Huang chose to focus on comparing the first two decades of the reform era because they provide the sharpest contrast in policy orientations. Specifically, the period from 1979 to 1988 (or the 1980s) is characterized by a wide range of policies that in general "moved China in the liberal direction of the Washington Consensus", namely, Chineseadopted private entrepreneurship, financial reforms and some unprecedented political opening. (Ash, 2006) characterized this trend with the general term of "decollectivization". In line with these observations, (Tisdell, 2009) emphasized that this period experienced an increased scope for private investment, greater freedom in geographical labour movement as well as larger variability in consumer goods and services.

Although political and civil liberties are still restricted, as Huang stated it "...every important political reform...was instituted in the 1980s" (p.13), including several specifically designed enhancements of checks and balances on the power of the Chinese Communist Party (CCP) as well as increases in the National People's Congress (NPC) ability to evaluate officials in the executive branch and the courts. In contrast, China reversed most of these policies towards more statist directions during the 1990s. As an illustration of the increased state control during this later period, Huang cited the large, rapid expansion in the number of government officials and fix-asset investments. In addition, according to a 2007 article by $\mathrm{Wu}$ Min, a professor at the Party school under the Shanxi Provincial Party Committee, the overseeing power of the NPC was reduced greatly in this period. (Huang, 2009) also concluded that it was the early local experiments with financial liberalization and private ownership in the 1980 that generated an initial burst of rural entrepreneurialism and laid the true foundation for the Chinese miracle.

\section{Second major argument: The role of private entrepreneur- ship}

Another significant factor contributed to Huang's counterview to the Beijing Consensus is the confirmation of the central role of private entrepreneurship in economic growth since the earliest phases of the Reform era.

One common belief among mainstream economists was that Chinese growth was mainly driven by collectively-owned firms, chief among which were the Township and Village Enterprises (hereafter TVEs). While discussing the role of TVEs in driving China's rural industrialization and fostering entrepreneurship in early reform stages, (Xu \& Zhang, 2009) show that TVEs served as a major stepping stone for institutional changes when legal protections of private property rights were not in place. (Roland, 2000) acknowledged the challenge that Chinese TVEs posed to traditional economic claims, and agreed that the success of a publicly owned structure lacking incentives to perform effectively became very confusing. Nobel laureate Joseph Stiglitz (Stiglitz, 2006) considered TVEs a form of public ownership that prevents plundering while achieving the efficiency of private-sector companies. These well-established observations seem to undermine the weight of China private sector. 


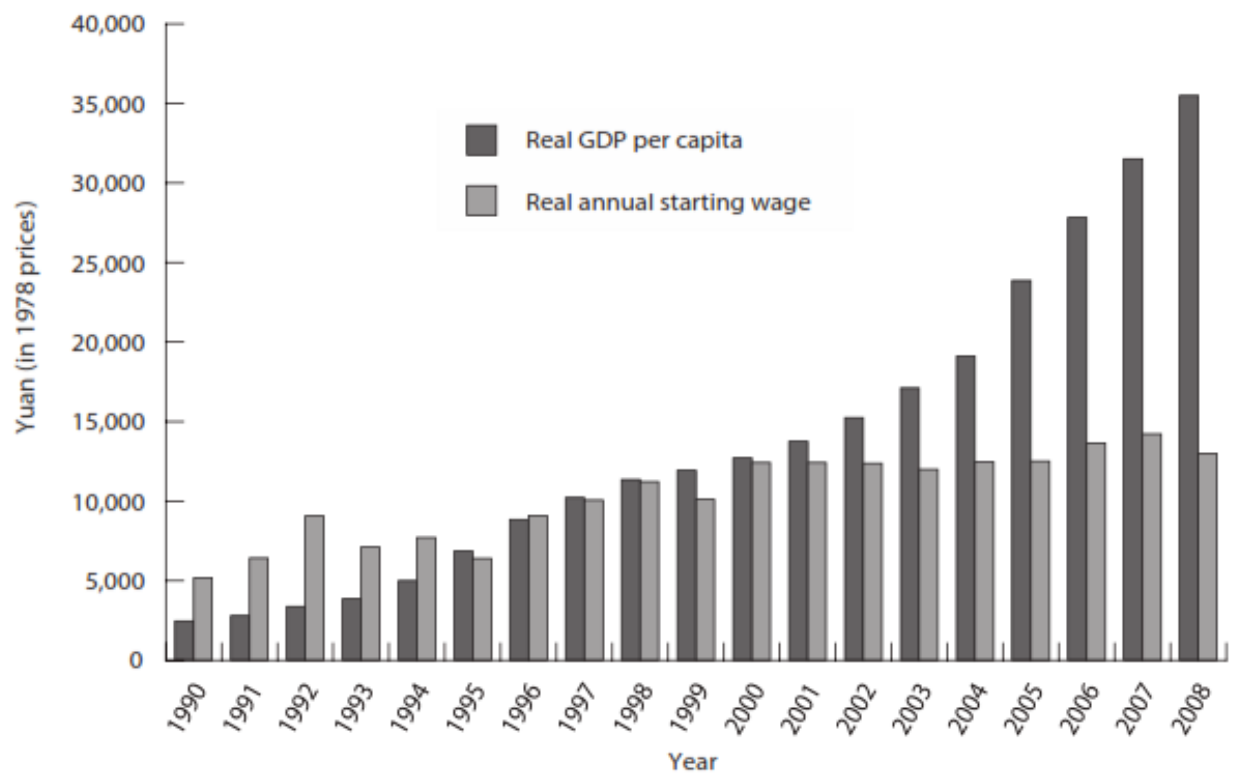

Source: "Rural Migration Survey," provided by Department of Sociology, Zhongshan University, Guangzhou.

Figure 2: Real per capita GDP and real starting wage of rural migrant workers in Guangdong (values in 1978 prices). Originally from (Huang, 2011), (p.11).

Despite these comments, Huang attributed the underestimation of the private sector's role in mainstream researches to a failure to consider relevant empirical evidences and a misunderstanding of TVEs' structure. He made two important arguments: first, in 1985 the number of TVEs is far greater than the commune and brigade enterprises at the beginning of the reform, thus undermining the presupposition that TVEs originated from state-owned enterprises; second, while TVEs do include a number of genuine collectively-owned firms, the majority of them was in fact privately owned and acknowledged among rural communities while expressing themselves as TVEs on paper only. In addition, it was these private TVEs that contributed greatly to not only most of provincial gross output but also the poverty reduction process in China during the reform period $^{2}$. (Xu \& Zhang, 2009) further developed Huang's viewpoint, attributing the success of these businesses to their unique nature: defined ownership of leading entrepreneurs backed up by property protection provided by strong ties with local governments. Particularly, while the community government acts as a representative (or the de facto owner) of TVEs, control is passed to local managers and employees (who may be located within the same communal area with the government officials) via collectively signed contracts. Because of the strong social norm linkages, the representatives would likely to provide TVEs with access to state-owned resources and property

\footnotetext{
${ }^{2}$ (Xu \& Zhang, 2009) reported that the total industrial output of TVEs grew at an average annual rate of $28.1 \%$, doubling that of the national sector and more than tripled that of the state sector during 1981-1990 (p.4).
} 
protection due to regional competition. Though there is still much to argue about the exact role of local governments, these observations confirm the positive effect they had on improving TVEs' productivity. This may be a partial solution to the incentive puzzle posed by (Roland, 2000).

\section{Insights from 2015 market crashes}

It would be fruitful to close our analysis with some discussion on how effective the state control, following Beijing Consensus' ideas, fairs when used to foster economic stabilization. A stark example could be quoted by relating to what happens in the most recent China market crash in mid July and August 2015. During this period, China stock markets suffered an enormous downturn, basically wiping out all profit gained from the strong rally since March 2015. According to (The Economist, 2015), the most astonishing aspect of this event is not the dramatic losses ${ }^{3}$, but the averse effect of intervention from China's regulators.

Given the recent stabilized performance of China various asset markets as well as her slow but steady growth rate, it is hard to understand how stock prices could fall so low, to a level far beyond anticipated correction for overvalued stocks. Although the reasons of the initial crash lie within many factors, worsening the downturn were a plethora of drastic countermeasures from regulators in what is now believed to be a panic mode: first a cut in interest rate, then prevention of stock short selling and new stock issues (IPOs), followed by injections of central bank cash to buy existing stocks. All of this is backed up by a large confidence restoring campaign by the state media. As it turned out, market value continued to drop after each announcement of these measures.

The most important lesson learned from China's reaction in this dramatic event is that the state tend to hold its agenda at all costs, but was hard pressed to keep it, especially when trying to reverse the more liberal effects of market forces. The failure of stock market to follow the design of regulators is, in that respect, now quite understandable. It shows that the China state control over her economy, powerful though it may be, cannot indefinitely foster growth when China has begun to integrate deeply into the world's market. In other words, the rigid principles of the original Beijing Consensus may not be appropriate given contemporary contexts, confirming Huang's foreseeing insight four years earlier.

\section{Conclusion}

In general, (Huang, 2011) advocated the idea that China experienced phenomenal growth when adopting a gradualist approach, and an experimentalist model that continuously evolves overtime rather than a rigid, constant involvement of state control policies. In my opinion, this statement is significant considering its existence among the widely accepted view of a fixed Chinese ideology. While the author interpreted China's success in the last three decades in light of a movement toward economic and political liberalism, he also does not approve of a quick conversion to market fundamentalism. His view resonated with that of (Ramo, 2004), who argues that there is no perfect solution for stable economic growth, and that the only true path to success is one that is dynamic, as no one plan works for every situation.

In terms of methodology and data, I agree with Huang's attempt to use personal income to reassess the Beijing Consensus, thus introducing the welfare point of view. Huang's motivation is

\footnotetext{
${ }^{3}$ Estimated to be equivalent to $8.5 \%$ drop for the Shanghai Composite Index on the newly dubbed "Black Monday of 2015" - August 24 (The Guardian, 25 Aug 2015).
} 
similar to that of many other authors, including (Tisdell, 2009), who stated that GDP alone and market-based measures of per capita income can be a poor indicator of human welfare. (Tisdell, 2009) proposed the use of the Human development Index (HDI) and partly came to the same conclusion as Huang: China did progressed significantly in its reform period.

However, as Huang had pointed out in the first part of his paper, the reliability of economic data, particularly from China, is far from perfect. As far as methodology concerns, I believe there would always be room for improvement with the use of better, more transparent measurement of growth in future analyses. Another suggestion is that a comparison between Chinese's performance with that of other developing countries, after controlling for country fixed-effects, could be a valuable addition to support Huang's view. This would help clarify whether Chinese's growth rate should be considered less impressive in terms of personal income when compare with other countries which may or may not undergo the same reforming principles. Furthermore, to support his main argument the author should provide a comparison between the living standards of states that centralized on indigenous private entrepreneurship and states favoring state-led capitalism.

Throughout the later part of this paper we can see that TVEs' contribution in Chinese economic growth was undeniable. However, it is advisable for academics to look deeper at the features that enabled TVEs to fulfill their role, rather than focus on clarifying their ownership nature. Huang, in an attempt to provide a reasonable examination of Beijing Consensus' empirical bases, indicated that property rights and private entrepreneurship provided the dominant stimulus for high growth and lower levels of poverty. It is notable that the author presented many convincing evidence supporting the dominance of private TVEs. Although there is continuing debate around their ownership, one thing is certain: it is the economic freedom and relative political dependence given to these entities that made them so successful, especially in the rural areas. 


\section{References}

Ash, R. (2006). Squeezing the peasants: Grain extraction, food consumption and rural living standards in Mao's China. The China Quarterly, 188, 959-998.

Huang, Y. (2008). Capitalism with Chinese characteristics: Entrepreneurship and the State. Cambridge: Cambridge University Press.

Huang, Y. (2009). Private ownership: the real source of China's Economic miracle. The McKinsey Quarterly(1), 148-159.

Huang, Y. (2011). Rethinking the Beijing Consensus. Asia Policy, 11(1), 1-26.

International Monetary Fund. (2014, April). WEO Database. Retrieved from http:// www.imf .org/external/pubs/ft/weo/2014/01/weodata/

Jiang, Y. (2011). Rethinking the Beijing consensus: how China responds to crises. Pacific Review, 24(3), 337-356.

Lau, L. J., Qian, Y., \& Roland, G. (2000). Reform without Losers: An Interpretation of China's Dual Track Approach to Transition. The Journal of Political Economy, 108(1), 120-143.

Ramo, J. C. (2004). The Beijing Consensus. Retrieved from http://fpc.org.uk/ publications/TheBeijingConsensus

Rodrik, D. (2006). Goodbye Washington consensus, hello Washington confusion? A Review of the World Bank's cconomic growth in the 1990s: Learning from a decade of reform. Journal of Economic Literature, 55(2), 973-987.

Roland, G. (2000). Transition and Economics: Politics, Markets, and Firms (Vol. 2). Cambridge, Mass: MIT Press.

Stiglitz, J. (2006). The transition from communism to market: A reappraisal after 15 years. European Bank for Reconstruction and Development Annual Meeting.

The Economist. (2012). The next chapter: Beyond growth. Retrieved from http:// www. economist.com/node/21555765

The Economist. (2015). China's stockmarket crash: A red flag. The Economist. Retrieved from http://www.economist.com/blogs/freeexchange/2015/07/chinas -stockmarket-crash

The Guardian. (25 Aug 2015). China's 'Black Monday' sends markets reeling across the globe - as it happened. The Guardian. Retrieved from http://www. theguardian.com/business/live/2015/aug/24/global-stocks -sell-off-deepens-as-panic-grips-markets-live

Tisdell, C. (2009). Economic Reform and Openness in China: China's Development Policies in the Last 30 Years. Economic Analysis and Policy, 39(2), 271-294.

Xu, C., \& Zhang, X. (2009). The evolution of Chinese entrepreneurial firms: Townshipvillage enterprises revisited (IFPRI discussion papers No. 854). International Food Policy Research Institute (IFPRI). Retrieved from http://ideas.repec.org/p/ fpr/ifprid/854.html 